\title{
A Study of Anxiety and Depression among School and College Going Adolescents-A Comparative Study
}

\author{
Madhuchandra, M.K, \\ Research Scholar, Department of Studies in Psychology, Manasagangothri, University of Mysore, Mysore
}

\begin{abstract}
The aim of the present study is to find out the level of anxiety and depression among School and college going adolescents. A total of 113 adolescents were selected from various schools (61) and college (52) from Mysore city. Multiphasic Personality Questionnaire (MPQ) by Murthy H.N was used to assess the level of anxiety and depression. The Two Way Analysis of Variance was used to study two factors and the interaction between two variables. Result of the study revealed that school and college going adolescent studying at varies school and colleges in Mysore do not show any significant difference in depression and anxiety. Between genders comparison reveals that boys and girls do not differ significantly on anxiety and depression. However Depression is more than anxiety among school and college going adolescent.
\end{abstract}

Keywords: Anxiety, Depression

\section{Introduction}

Adolescence is a time of rapid change encompassing physical, mental, social and emotional realm. Majority of adolescents experience frustration and confusion in taking decision while passing through childhood to adulthood. Adolescence is referred to as the "stormy" period of life", „crisis of youth", ,clumsy age", ,difficult age" etc. The period of adolescence ranges from 12 to 18 years (Erikson 1968) which is particularly crucial and also it is the time the question of one"s basic ego identity is met and must be resolved.

The present era in which we live has been called the "Age of Anxiety" and anxiety manifestations are certainly widespread. Anxiety is an emotion characterized by apprehension and anticipation of future danger or misfortune accompanied by a feeling of dysphorea or somatic symptoms of tension (American Psychiatric Association, 2000). The perceived danger may be either an internal or an external fear. Anxiety is a psychic condition of height and sensitivity to some perceived threat, risk or danger. The perceived danger may be either an internal or external fear. The physiological manifestation of anxiety such as elevated blood pressure, cardiac discomfort (Gorman, Fyer \& Gliklich, 1981), dizziness, dry mouth, irregularities in breathing, muscular skeletal disturbances may present as symptoms of activation of autonomic nervous system. Anxiety is a normal reaction to a situation where immediate danger exists and may result in physical harm (Goldstein, 1940). Anxiety is also a normal response to a situation that poses a threat to self - esteem or psychological well being (Le Doux, 2000) occurs in situations where there is no real physical or psychological danger or when the emotional reaction is disproportionate in intensity to the actual danger (Spielberger \& Rickman, 1990). However all the theories are convinced that apprehension and anticipation of future danger and somatic symptoms of tension are inevitably involved in it. Nowadays nobody is abstained from the negative effects of anxiety. So there is a strong need to find out an effective solution and attempts have been made in this regard in terms of scientific research.

Depression occurs due to loss of an ambivalent love object, narcissistic injury resulting from discrepancies between selfrepresentation and wished-for self-image or inconsistency between the self-representation and moral and ethical values built into ego ideal (Milrod 1988; Rubinfine 1968). Although depression is throughout the life cycle, the incidence of depression rises sharply during adolescence a period of great turmoil for many people. Recent figures also suggest that the average age of onset of adolescent depression has been decreasing over the past decade (Lewinsohen, et al., 1993 Speir et al., 1995).

Maarten et al., (2009) examined Different types of Internet use, depression, and social anxiety: The role of perceived friendship quality. Sample consists of 307 Dutch middle adolescents (average age 15 years) on two waves with a oneyear interval. Result of the study revealed that adolescents who perceive low friendship quality, Internet use for communication purposes predicted less depression, whereas Internet use for non-communication purposes predicted more depression and more social anxiety.

Narayan R Mutalik et al., (2016) conducted a study on depression, anxiety and stress among college students in Bagalkot; A College Based Study. Sample consists of 133 undergraduate students from Govt. First Grade Collage, Bagalkot, was included based on universal sampling method. Depression Anxiety, Stress Scale (DASS-21) and General health questionnaire (GHQ-28) were used for collecting the data. Result of the study revealed that Level of anxiety was more than depression followed by stress. Females had significant emotional distress as compared to males. Study also found that high grade of depression, anxiety and stress among undergraduate students.

Candice et al., (2009) examined sleep problems and their relation to cognitive Factors, anxiety, and depressive symptoms in Children and adolescents. The total sample for 


\section{International Journal of Science and Research (IJSR) \\ ISSN (Online): 2319-7064}

Index Copernicus Value (2015): 78.96 | Impact Factor (2015): 6.391

the study covered was 175. Result of the study shows significant associations between sleep problems and both anxiety and depressive symptoms, though results varied by age. Depressive symptoms showed a greater association with sleep problems among adolescents, while anxiety symptoms were generally associated with sleep problems in all youth

Cecilia (2005) conducted a study on frequency and patterns of mental health services utilization among adolescents with anxiety and depressive disorders. Sample of 1,035 adolescents were selected randomly from 36 schools. The co morbidity rate within the anxiety disorders was relatively low (14.1\%). However, the co morbidity of anxiety disorders with other psychiatric disorders was high. Approximately half (51\%) of the anxious adolescents had other psychiatric disorders. The most common co morbid pattern was that of anxiety and depressive disorders. Among those with both anxiety and depressive disorders, a majority of them $(72 \%)$ had anxiety before that of depression. The effect of co morbidity on mental health services utilization was stronger in males than females.

In the high light of the above background the present study was conducted to study of anxiety and depression among school and college going Adolescents.

\section{Objectives}

The objectives of the present study are as follows: A) to study the anxiety and depression of school and college adolescent. B) To assess gender variance of anxiety and depression among school and college adolescent.

\section{Hypotheses}

The following hypotheses were framed for the study: A) School and college adolescent differ in Anxiety and Depression B) There is no significant difference between male and female adolescents on Anxiety and Depression.

\section{Method}

\section{Sample}

The sample consisted of 113 (boys-52 and girls-61) students randomly chosen from various schools (N-61) and colleges (N-52) in Mysore City. The age group of the sample ranged from 15 to 19 years.

\section{Tools}

1) A socio-demographic Data Sheet was used to gather information on the age, gender, education under the details.

2) Multiphasic personality Questionnaire: This was prepared and standardized by Dr. H.N. Murthy, NIMHANS for the Indian Clinical Population. The Questionnaire has 7 clinical scales as follows: Anxiety Scale, Hysteric Scale, Paranoid Scale, Schizophrenia Scale, Manic Scale, Psychopathic Scale and Depression Scale. For the present study only Anxiety and Depression Scales were used. The Scoring is done according to scoring key. The cut off point for depression is 5, and for Anxiety 11.

\section{Procedure}

After taking permission from the consent authority, subjects were assessed on Multiphasic personality Questionnaire (MPQ). Further, data were analyzed using descriptive statistics.

\section{Results}

Table 1: Showing Mean, SD and F value for Boys and Girls under school and college going adolescents Anxiety and depression

\begin{tabular}{|c|c|c|c|c|c|c|}
\hline \multirow[b]{2}{*}{ Institute } & \multirow[b]{2}{*}{ Gender } & \multirow[b]{2}{*}{$\mathrm{N}$} & \multicolumn{2}{|c|}{ Anxiety } & \multicolumn{2}{|c|}{ Depression } \\
\hline & & & Mean & SD & Mean & SD \\
\hline \multirow{3}{*}{ School } & Boys & 28 & 7.82 & 3.58 & 5.82 & 2.84 \\
\hline & Girls & 33 & 8.15 & 4.89 & 4.82 & 2.40 \\
\hline & Total & 61 & 8.00 & 4.31 & 5.28 & 2.64 \\
\hline \multirow{3}{*}{ College } & Boys & 24 & 7.79 & 3.49 & 5.79 & 2.72 \\
\hline & Girls & 28 & 8.75 & 5.14 & 5.50 & 2.52 \\
\hline & Total & 52 & 8.31 & 4.44 & 5.63 & 2.59 \\
\hline \multirow{3}{*}{ Total } & Boys & 52 & 7.81 & 3.50 & 5.81 & 2.76 \\
\hline & Girls & 61 & 8.43 & 4.97 & 5.13 & 2.46 \\
\hline & Total & 113 & 8.14 & 4.35 & 5.44 & 2.61 \\
\hline \multicolumn{2}{|c|}{ F ( Group) } & \multicolumn{3}{|c|}{$\mathrm{F}=0.117 ; \mathrm{P}=0.733$} & \multicolumn{2}{|c|}{$\mathrm{F}=0.434 ; \mathrm{P}=0.511$} \\
\hline \multicolumn{2}{|c|}{ F (Gender) } & \multicolumn{3}{|c|}{$\mathrm{F}=0.599 ; \mathrm{P}=0.441$} & \multicolumn{2}{|c|}{$\mathrm{F}=1.713 ; \mathrm{P}=0.193$} \\
\hline \multicolumn{2}{|c|}{ F (interaction) } & \multicolumn{3}{|c|}{$\mathrm{F}=0.142 ; \mathrm{P}=0.707$} & \multicolumn{2}{|c|}{$\mathrm{F}=0.517 ; \mathrm{P}=0.474$} \\
\hline
\end{tabular}

On the whole the result found that school and college adolescent did not differ significantly on anxiety scores $(\mathrm{F}=1.117 ; \mathrm{P}=0.733)$. With respect to gender wise score $(\mathrm{F}=0.599 ; \mathrm{p}=0.441)$ of Boys and Girls and the interaction between group and gender score $(\mathrm{F}=1.142 ; \mathrm{P}=0.707)$ was also found to be non-significant.

On the whole the result found that school and college going adolescent did not differ significantly on depression scores $(\mathrm{F}=0.434 ; \mathrm{P}=0.511)$. With respect to gender wise score $(\mathrm{F}=1.713 ; \mathrm{p}=0.193)$ of Boys and Girls and the interaction between group and gender score $(\mathrm{F}=0.517 ; \mathrm{p}=0.474)$ was also found to be non-significant.

Table 2: Showing the group "s percentage on the following psychopathological tendencies

\begin{tabular}{|c|c|}
\hline Psychopathological tendencies & Group "s percentage \\
\hline Depression & $54.9 \%$ \\
\hline Anxiety & $31 \%$ \\
\hline
\end{tabular}

Table 2 shows that depression is more among adolescents as $54.9 \%$ of the group has shown this tendency followed by anxiety i.e. only $31 \%$.

\section{Discussion}

The main objective of the current research is to study the Anxiety and depression of school and college adolescent. The hypothesis states that School and college adolescent differ in Anxiety and Depression. Statistical method of ANOVA has been applied to measure between-subjects by SPSS (version 20) to test the hypothesis. Outcome of the study it was found that school and college adolescent did not differ significantly in their anxiety and depression. Though no studies directly available in this regard, a study by Linda et al., (2010) examined the association of depression and 


\section{International Journal of Science and Research (IJSR) \\ ISSN (Online): 2319-7064}

Index Copernicus Value (2015): 78.96 | Impact Factor (2015): 6.391

anxiety with health-related quality of life in cancer patients with depression and/or pain. Result revealed that Anxiety and depression have strong and independent associations with mental health domains and somatic symptom burden in cancer patients. Study by Brady et al., (1992) examined comorbidity of anxiety and depression in children and adolescents. Result revealed that $15.9 \%$ to $61.9 \%$ of children identified as anxious or depressed have co-morbid anxiety and depressive disorders and that measures of anxiety and depression are highly correlated.

The second objective of the current research is to assess gender variance of Anxiety and Depression among school and college adolescent. Hypothesis of the study states that: There is no significant difference between Boys and Girls adolescents on Anxiety and Depression. Findings of the study revealed that Boys and Girls adolescent do not differ significantly on anxiety and Depression. The finding was supported by Marco Piccinelli et al., (2000) studied on Gender differences in depression. Result shows that adverse experiences in childhood, depression and anxiety disorders in childhood and adolescence, socio-cultural roles with related adverse experiences, and psychological attributes related to vulnerability to life events and coping skills are likely to be involved. Genetic and biological factors and poor social support, however, have few or no effects in the emergence of gender differences.

The group is dominated by the Depression as the $54.9 \%$ of them have shown this tendency, whereas only $31 \%$ of them have shown anxiety tendency.

\section{Conclusion}

It may be noted from the above studies that school and college going adolescent studying at varies school and colleges in Mysore do not show any difference in depression and anxiety. Between genders comparison reveals that Boys and Girls do not differ significantly on anxiety and depression. However Depression is more than anxiety among school and college going adolescent. The Finding of the study may be utilized to understand and to identify which psychopathological tendencies dominate in today ${ }^{\text {ee }} \mathrm{s}$ adolescents. The study may help to offer suggestions and guidance to adolescent groups in reducing depression. The study may also help in offering guidelines to parents, teachers and educational institutions who are concerns with adolescents.

\section{Acknowledgments}

The author appreciates all those who participated in the study and helped to facilitate the research process.

\section{Conflict of Interests}

The author declared no conflict of interests.

\section{References}

[1] American Psychiatric Association. (2000). Diagnostic and Statistical Manual of Mental Disorders ( $\left.4^{\text {th }} \mathrm{Ed}\right)$, Text Revision. APA, Washington DC.

[2] Brady, Erika U., Kendall Philip, C. (1992). Comorbidity of anxiety and depression in children and adolescents. Journal of Psychological Bulletin, 111(2), 244-255.

[3] Candice, A. Alfano., Alan, H. Zakem., Natalie, M. Costa., Leslie, K. Taylor., \& Carl, F. Weems. (2009). Sleep problems and their relation to cognitive Factors, anxiety, and depressive symptoms in Children and adolescents. Journal of depression and anxiety, 26, 503-512.

[4] Cecilia, A. Essau. (2005). Frequency and patterns of mental health services utilization among adolescents with anxiety and depressive disorders. Journal of depression and anxiety, 22(3), 130-137.

[5] Erikson, E.H. (1968). Identify: Youth and crimes. New York, Norton,.

[6] Glasser, P.J., \& Navarro, E. (1964). Structural Problems of the one - parent family, Journal of Social Issues. 21.1; 98-109.

[7] Goldstein, K. (1940). Human Nature in the light of Psychopathology. Harvard University Press, Cambridge, MA.

[8] Gorman, J.M., Fyer, A.J., \& Gliklich, J. (1981). Mitral Valve prolapsed and panic disorders. Effect of imipramine. In Klein, D.F and Rabkin, J.G (Eds) Anxiety: New research and changing concepts. New York: Raven Press.

[9] Joseph, E. LeDoux., Jean-Marc Fellous., \& Jorge L. Armony. (2000). Emotional Circuits and Computational Neuroscience. $2^{\text {nd }}$ edit, Cambridge, MIT Press.

[10] Linda F. Brown., Kurt Kroenke., Dale E. Theobald., Jingwei Wu,. \& Wanzhu Tu. (2010). The association of depression and anxiety with health-related quality of life in cancer patients with depression and/or pain. Journal of psychological, social and behavioural dimensions of cancer, 19(7), 734-741.

[11] Lewinsohn, P.M., H., \& Roberts, R.E. (1993). Adolescent psychology: I. Prevalence and incidence of depression and other DSM-III-R disorders in high school students. Journal of Abnormal Psychology, 102, 133-144.

[12]Milrod, D. (1988). A current view of the psychoanalytic theory of depression - with notes on the role of identification, orality and anxiety. The journal of Psychoanalytic Study of the Child, 43, 83-99.

[13] Marco Piccinelli., \& Greg Wilkinson. (2000). Gender differences in depression.

[14] The British Journal of Psychiatry, 177 (6) 486492.

[15] Maarten, H.W., Susan, J.T.B., M. Delsing., Tom, F.M., \& Wim, H.J. M. (2009). Different types of Internet use, depression, and social anxiety: The role of perceived friendship quality. Journal of Adolescence, 32, 819-833.

[16] Narayan R Mutalik., Shankar Moni., Choudhari,S.B., Govind, S. Bhogale. (2016). Depression, Anxiety, Stress among College Students in Bagalkot: A College Based Study. The International Journal of Indian Psychology, 3(4), 68. 


\section{International Journal of Science and Research (IJSR) \\ ISSN (Online): 2319-7064}

Index Copernicus Value (2015): 78.96 | Impact Factor (2015): 6.391

[17] Rubinfine,D. L. (1968). Notes on a theory of depression. The Psychoanalytic Quareterly, 37, 400417.

[18] Speir,T.W., HA Kettles, A Parshotam, PL Searle, LNC Vlaar. (1995). A simply kinetic approach to derive the ecological dose value, ED50, for the assessment of $\mathrm{Cr}$ (V1) toxicity to soil biological properties. Soil Biology \& Biochemistry, 27, 801-810

[19] Spielberger, C. D., \& Rickman, R. L. (1990). Assessment of state and trait anxiety. In N. Sartorius, V. Andreoli, G. Cassano, L. Eisenberg, P. Kielkolt, P. Pancheri, \& G. Racagni (Eds.), Anxiety: Psychobiological and clinical perspectives (69-83). New York: Hemisphere Publishing. 